\title{
The discipline of history and the technologies: a challenge for the present time
}

\section{A disciplina de história e as tecnologias: um desafio do tempo presente}

\section{La disciplina de historia y tecnologías: un desafío del tiempo actual}

\author{
Simone Weber Cardoso Schneider ${ }^{1}$ iD, Adriana Duarte Leon $^{1}$ (iD
}

${ }^{1}$ Instituto Federal Sul Rio-grandense, Pelotas, Rio Grande do Sul, Brasil.

Corresponding author:

Simone Weber Cardoso Schneider

Email: simonewcs@gmail.com

How to cite: Schneider, S. W. C., \& Leon, A, D. (2021). The discipline of history and the technologies: a challenge for the present time. Revista Tempos e Espaços em Educação, 14(33), e14109.

http://dx.doi.org/10.20952/revtee.v14i33.14109

\begin{abstract}
Based on the understanding that the use of Information and Communication Technologies (ICT) can contribute positively to the meaning of historical knowledge and to the motivation of students in the school environment, we investigate, in the Middle School level, from public schools, in the city of Pelotas/RS, how History teachers perceive ICT and how they are used in their pedagogical practice. Considering the number of teachers that we wanted to access and the short time for conducting the research, we opted for the application of an inquiry with the teachers of the specific area and we obtained a return of $68 \%$ of the teachers. We found that they identify students' motivation when ICT are used in the school environment; however, its use is limited by the lack of structural resources in the institutions and by the lack of continuing education for educators on the use of ICT in pedagogical practice.
\end{abstract}

Keywords: History. Pedagogical practice. Technologies.

\section{RESUMO}

Compreendendo que a utilização das Tecnologias de Informação e Comunicação (TIC) pode contribuir de forma positiva para a significação do conhecimento histórico e para a motivação dos estudantes no ambiente escolar, investigamos como os professores de História, do 6으 ao 9ㅇaㅁ ano, da Rede Municipal de Ensino da cidade de Pelotas/RS percebem as TIC e como as inserem em sua prática pedagógica. Considerando a quantidade de professores que queríamos acessar e o curto tempo para a realização da pesquisa, optamos pela aplicação de um questionário junto aos docentes da área específica e obtivemos um retorno de $68 \%$ dos professores. Constatamos que eles identificam a motivação dos estudantes quando as TIC são utilizadas no espaço escolar; contudo, 
sua utilização é limitada pela carência de recursos estruturais nas instituições e pela falta de uma formação continuada para os educadores sobre a utilização das TIC na prática pedagógica.

Palavras-chave: História. Prática pedagógica. Tecnologias.

\section{RESUMEN}

Entendiendo que el uso de las Tecnologías de la Información y la Comunicación (TIC) puede contribuir positivamente al significado del conocimiento histórico y a la motivación de los estudiantes en el entorno escolar, investigamos cómo los profesores de Historia, desde el sexto hasta el noveno grado, de la Red Municipal de Educación de Pelotas / RS percibe las TIC y cómo se insertan en su práctica pedagógica. Teniendo en cuenta la cantidad de maestros a los que queríamos acceder y el poco tiempo para llevar a cabo la investigación, optamos por la aplicación de un cuestionario con maestros en el área específica y obtuvimos un retorno del $68 \%$ de los maestros. Descubrimos que identifican la motivación de los estudiantes cuando las TIC se utilizan en el entorno escolar; sin embargo, su uso está limitado por la falta de recursos estructurales en las instituciones y la falta de capacitación continua de educadores sobre el uso de las TIC en la práctica pedagógica. Palabras clave: Historia. Práctica pedagógica. tecnologías.

\section{INTRODUCTION}

O presente artigo compartilha os resultados de uma pesquisa realizada no ano de 2018, junto às escolas da rede pública municipal da cidade de Pelotas/RS/Brasil. A investigação em questão buscou compreender como os professores de História faziam uso das Tecnologias de Informação e Comunicação (TIC) na sua prática pedagógica, quais objetivos pretendidos ao utilizarem os recursos tecnológicos, como utilizam e, no caso de não utilizarem, os motivos da não utilização. Tendo em vista que a sociedade atual está imersa nas tecnologias e que as crianças, de forma geral, nascem e crescem em meio a esse contexto, procuramos compreender como os professores percebem e inserem as tecnologias na sala de aula.

Essa análise é relevante, pois muitas crianças, adolescentes e jovens dispõem de determinadas tecnologias para seu uso pessoal e pretendem tê-las também no espaço escolar. Prenski (2001) denomina esses estudantes que nasceram e cresceram envoltos em tecnologias como "nativos digitais". Atualmente, esse é o perfil da maioria dos estudantes de nossas escolas e nem sempre os professores usam as tecnologias em sala de aula. Ao negar a existência deste mecanismo que faz parte da rotina dos estudantes, deixam de aproveitar um recurso potente para a aprendizagem dos discentes.

Pretendemos, com esta reflexão, contribuir com os estudos acerca do Ensino de História e potencializar metodologias que utilizem as TIC, a fim de tornar o ensino dessa disciplina motivador e agregador na aprendizagem.

\section{A POTENCIALIDADE DAS TECNOLOGIAS NO PROCESSO EDUCATIVO}

Atualmente, vivemos cercados das mais variadas tecnologias, que se renovam e se multiplicam em um ritmo muito veloz. A tecnologia é tudo aquilo que o ser humano criou, que foi necessário tempo e estudo para a sua criação e aperfeiçoamento, o que levou tempo para aprender e ensinar e tem como objetivo qualificar de forma positiva a existência da humanidade. Segundo Kenski (2007, p. 24), "ao conjunto de conhecimentos e princípios científicos que se aplicam ao planejamento, a construção e a utilização de um equipamento em um determinado tipo de atividade, chamamos de tecnologia". Brito e Purificação (2006, p. 18) também dizem que "tecnologia é a aplicação do conhecimento científico para obter-se um resultado prático". Nesse trabalho, falamos em uma tecnologia digital, que se dá a partir de eletrônica e microeletrônica. Essas tecnologias se desenvolveram especialmente durante a Segunda Guerra Mundial (1939-1945) 
e, posteriormente, no período da Guerra Fria (1945-1991), quando Estados Unidos e União Soviética disputaram a hegemonia mundial, logo após a Segunda Guerra. Esse foi um período de grande desenvolvimento científico e tecnológico. Segundo Kenski (2007, p. 16), o período da Guerra Fria "impulsionou a ciência e a tecnologia de forma jamais vista na história da humanidade".

Atualmente, a tecnologia se transforma de forma muito rápida, já que estamos vivendo na chamada sociedade da informação, onde através dos meios de comunicação e especialmente da internet podemos estar conectados e recebendo informações o tempo todo. Alves $(2019$, p. 04) afirma que "o processo de digitalização de uma parte expressiva das atividades da sociedade" estimulou a consolidação do uso das tecnologias no cotidiano das pessoas. Essas tecnologias não se limitam ao espaço de lazer, entretenimento e trabalho, mas chegam ao cenário escolar e estão sendo utilizadas na prática pedagógica pelos professores.

A escola tem um compromisso ético com a sociedade e deve oferecer uma formação ampla e conectada com a realidade do indivíduo. Assim, a chamada sociedade da informação ${ }^{1}$ pode se tornar a sociedade do conhecimento se soubermos aproveitar as potencialidades oferecidas pelas tecnologias. Contudo, como bem destaca Brito e Purificação (2006), Kensky (2007) e Moran (2009), a tecnologia não vai solucionar os problemas enfrentados na educação, mas pode auxiliar na construção de uma escola onde os estudantes estejam conectados ao espaço escolar e compreendam-se como potencial agregador e ativo no processo de aprendizagem.

Incluir as tecnologias no processo pedagógico é abarcar a realidade do estudante no planejamento docente, tal uso implica em realizar um diagnóstico da turma para identificar o perfil do grupo e o uso que fazem das tecnologias. Todavia, incorporar as tecnologias a prática docente, pode implicar em uma demanda de aprendizado para os professores que por vezes não dominam tais ferramentas. Figueiredo e Rodrigues $(2020$, p.13) ao tratar do fazer docente destacam que "Identificar metodologias capazes de provocar situações de aprendizagens mediatizadas pelo uso das tecnologias digitais requer uma (re)organização de saberes e fazeres, que pode ser uma tarefa bastante complicada [...]".

Lévy (2010) diz que os professores podem intermediar o processo de aprendizagem e de pensamento com o uso das tecnologias, devendo acompanhar essa aprendizagem e propor a troca de saberes, pois as funções cognitivas podem sofrer influências do ciberespaço na medida em que as tecnologias afetam a memória, a imaginação, a percepção e o raciocínio. Isso é possível, considerando o acesso à internet e as diversas possibilidades deste recurso, que tem revolucionado a forma como os indivíduos se relacionam e acessam a informação. $O$ autor diz ainda que não se trata de usar a tecnologia na educação a qualquer custo, mas defende que a escola deve acompanhar as mudanças da sociedade e reformular sua metodologia de ensino, considerando tais mudanças.

Diversas pesquisas têm sido desenvolvidas com foco na utilização das tecnologias no campo educacional, abordando suas potencialidades, seus limites e seus desafios. Neste texto, trabalhamos com as TIC, que são o conjunto de aparatos tecnológicos que, através de suas funções de hardware, software e telecomunicações, permitem, entre outros, o acesso à comunicação e à informação e podem ter suas potencialidades utilizadas nos processos de ensino e aprendizagem.

As TIC tiveram seu maior avanço na década de 90, quando as informações passaram a ser recebidas e transmitidas de forma muito rápida, devido ao uso da internet. De acordo com Brito e Purificação (2006), a internet surgiu nos EUA em fins da década de 60, no auge da Guerra Fria e durante cerca de 20 anos seu uso era restrito ao meio acadêmico e científico, até sua liberação para fins comerciais em 1987. "A internet é uma gigantesca rede interconectada por milhares de diferentes tipos de redes, que se comunicam por meio de uma linguagem comum (protocolo) e um

\footnotetext{
${ }^{1}$ O norte americano Daniel Bell foi o primeiro a utilizar a expressão: “sociedade da informação", em 1973. Essa expressão reapareceu fortemente na década de 90 com a expansão da internet e das TIC. Nesse sentido, ver Sally Burch (2005).
} 
conjunto de ferramentas que viabiliza a comunicação e a obtenção de informações" (Brito \& Purificação, 2006, p. 91).

A popularização da comunicação e da informação está cada vez mais presente na sociedade atual, inclusive nas escolas, que buscam promover a inclusão digital dentro dos seus espaços. Percebemos o uso das tecnologias no dia a dia, auxiliando-nos na realização das mais diversas tarefas e, em alguns casos, a internet se torna obrigatória para viabilizar situações práticas do cotidiano como pagar uma conta, fazer uma inscrição, fazer um cadastro, solicitar um benefício, enfim. Além das atividades de lazer, comunicação e informação, as TIC têm ocupado um espaço na existência prática do sujeito; por consequência, é relevante pautar a sua utilização no espaço escolar.

A expansão do acesso à internet, ocorrida nos últimos 10 anos em todo o mundo, potencializou a criação e utilização de diversos softwares e aparelhos eletrônicos que se mantém conectados todo tempo e passam a fazer parte do nosso cotidiano, como: smartphones, tablet's, computadores, televisões, relógios, porta-retratos, entre outros que possibilitam uma comunicação $U_{\text {Ubíqua }}^{2}$ ao nosso redor e dessa forma facilitam o dia a dia.

Como docente, sempre busquei, na minha prática pedagógica, metodologias que motivassem os estudantes e ampliassem sua participação no processo de ensino e aprendizagem. Acreditando na potencialidade das tecnologias na prática pedagógica, sempre que possível busquei inseri-las e obtive resultados positivos. Ainda assim, cabe esclarecer que o simples uso de uma tecnologia não significa que os discentes ficarão motivados com a aula ou que terão melhoria na sua aprendizagem, pois depende de como o professor fará uso desse recurso, ou seja, mesmo utilizando as tecnologias, o professor pode estabelecer uma postura conservadora e estabelecer uma prática docente baseada na transmissão de conhecimentos, sem processo reflexivo, crítico ou lógico construtivo. Tal como Brito e Purificação (2006) e Kenski (2007) nos alertam, apenas o uso da tecnologia não é suficiente, pois não significa inovação da prática pedagógica. As tecnologias por si não inovam a prática docente, mas a forma como o professor insere e usa essa tecnologia no cotidiano pode ser um fator positivo para o desenvolvimento do processo de ensino e aprendizagem.

Há que se considerar que o professor possa se adaptar à sociedade da informação e utilizar as TIC como estratégia de aprendizado, especialmente para a disciplina de História, que de acordo com Guimarães (2015) ainda é trabalhada de forma convencional por muitos docentes que supervalorizam a memorização de informações, tornando, assim, as aulas desinteressantes, fora do contexto e da realidade ${ }^{3}$ dos alunos que, muitas vezes, não identificam sentido no que aprendem. Isso porque "muitos professores, ainda que reconheçam a importância e a necessidade de aperfeiçoamento, permanecem imersos em outras práticas, realizadas por meios educativos convencionais" (Guimarães, 2015, p. 365).

Oliveira (2012) nos alerta ao fato de que é perceptível, no Ensino Fundamental, o desinteresse dos estudantes pela disciplina de História, que é vista como matéria irrelevante e cansativa. O autor diz que é necessário desenvolver a capacidade do aluno de pensar historicamente, levando-se em conta as ideias já presentes em sua cultura, pois são suas vivências que darão sentido ao passado e o auxiliarão a incorporar os conceitos históricos, possibilitando-o a pensar historicamente. Ou seja, é necessário que os estudantes sejam sujeitos ativos no processo de aprendizagem e que o professor atue como mediador, facilitando a aprendizagem e instigando

\footnotetext{
${ }^{2}$ O termo Computação Ubíqua foi originalmente criado por Mark Weiser em 1991, no seu artigo "O Computador para o século XXI", para se referir a dispositivos conectados em todos os lugares de forma tão natural para o ser humano que acabaremos por não perceber que eles estão lá.

${ }^{3}$ Quando tratamos sobre a realidade, estamos nos referindo ao contexto de vida que os estudantes devem compreender a partir da história, ou seja, o entendimento que tem da sua realidade como sujeito social e histórico a partir da evolução da história vivida pelos homens.
} 
seus alunos a refletirem, questionarem e se apropriarem do conhecimento de forma dinâmica e colaborativa. Nessa lógica, professor e aluno devem trabalhar juntos na busca pelo conhecimento. Os assuntos estudados devem estar em conexão com a realidade e possibilitar uma análise crítica da sociedade e do sujeito histórico.

As tecnologias não devem ser utilizadas como simples mecanismos de troca, ao substituir uma explicação por um documentário ou um livro didático por slides, mas sim como interação, como ferramentas de busca pelo conhecimento, que o estudante pode e deve se apropriar para ampliálo sobre o mundo e a sociedade. Como diz Moran (2009, p. 31), "é importante humanizar as tecnologias: são meios, caminhos para facilitar o processo de aprendizagem". Kenski (2007) corrobora com a mesma ideia e afirma que cabe ao professor a árdua tarefa de garantir o melhor processo de ensino e aprendizagem e, nesse contexto, as tecnologias podem ser um ótimo caminho. A mesma autora diz que as TIC possibilitam mudanças nas formas de abordagem dos conteúdos pelo professor e a forma como os alunos as entendem. Porém, para isso, é preciso que se tenha conhecimento sobre como utilizar essas TIC, porque, quando utilizadas corretamente, podem contribuir para o aprofundamento do aprendizado.

Ensinar a utilizar de forma crítica as diversas tecnologias presentes no mundo contemporâneo também é uma das tarefas da escola. Exercitar a pesquisa em sites confiáveis, averiguar as informações recebidas e identificar os aspectos positivos e negativos arrolados neste universo virtual é um desafio para os estudantes e também para os professores ao utilizarem as tecnologias. Cardoso e Pestana (2020, p.13) ao analisarem a wikipédia que é um site de busca e de edição coletiva destacam que "é uma fonte a que recorrem alunos/estudantes de todos os níveis de ensino, para concretização de seus trabalhos escolares/acadêmicos. Assim importa promover uma leitura crítica dos recursos digitais". O exemplo da wikipédia é ilustrativo, considerando que é um site muito utilizado para pesquisa e nem sempre as informações são confiáveis. Utilizar a internet como espaço de pesquisa e produção de conhecimento, exige o cruzamento de dados e um olhar reflexivo para o que está dito.

\section{O CONTEXTO E O PERCURSO DA PESQUISA}

A presente pesquisa apresenta abordagem qualitativa, considerando o investigador como principal instrumento, pois ele realiza as conexões que possibilitam a interpretação dos dados. De acordo com Bogdan e Biklen (1994, p. 51), "os investigadores qualitativos estabelecem estratégias e procedimentos que lhes permitem tomar em consideração as experiências do ponto de vista do informante".

Também nos referenciamos em Minayo (2009, p. 21), quando diz que a pesquisa qualitativa "trabalha com o universo dos significados, dos motivos, das aspirações, das crenças, dos valores e das atitudes", ou seja, a pesquisa qualitativa busca interpretar as relações humanas. Contudo, buscamos neste trabalho compreender como se dá a utilização das TIC pelos professores de História do Ensino Básico, da Rede Pública Municipal de Ensino (RPME) do município de Pelotas. Tendo em vista a problemática anunciada, foi empregado, como recurso metodológico, a aplicação de questionário junto aos professores da rede. A escolha por esse instrumento de pesquisa considerou o limite de tempo estabelecido para a realização do trabalho. Lakatos e Marconi (2003) observam que o questionário permite uma economia de tempo, pois atinge um considerável número de pessoas simultaneamente, além de possibilitar respostas rápidas, por vezes precisas; maior liberdade para o sujeito responder devido ao anonimato; não interferência do pesquisador e a possibilidade de ser respondido em tempo e ocasião viável pelo sujeito.

Foram convidados para participar da pesquisa os professores que atuam no Ensino Fundamental da rede municipal e trabalham com turmas do 6ㅇ ao 9ㅇaㅇ, na zona urbana. O sexto ano foi estabelecido como marco inicial da pesquisa, considerando que disciplina de História é implementada neste ano de forma discriminada e com professor habilitado na licenciatura 
específica. As escolas da área rural não foram selecionadas, considerando a dificuldade de acesso e a carência de tempo da pesquisadora para acessar essas escolas.

A pesquisa foi realizada no ano de 2018. Na época, o município de Pelotas contava com 86 professores de História cadastrados na rede; destes descontamos os professores que atuavam na zona rural, professores em licença e professores que estavam ocupando, naquele momento, alguma função administrativa e, por consequência, não estavam exercendo a docência na sala de aula. Considerando tais deduções, foram entregues 54 questionários em 32 escolas da RPME de Pelotas. A diversidade de horários dos professores dificultou a entrega pessoal de alguns questionários pela pesquisadora, e alguns foram entregues aos respectivos coordenadores pedagógicos que se encarregaram de sua entrega e recolhimento junto aos professores da disciplina de História. A entrega e o recolhimento dos questionários foram realizados entre os dias 23/04/18 a 23/05/18. Salienta-se que a recolha dos referidos questionários se deu nas datas combinadas com os referidos professores ou coordenadores pedagógicos; todavia, alguns professores não o preencheram, alegando falta de tempo ou desinteresse em participar da pesquisa ${ }^{4}$.

A partir do exposto, contamos com a distribuição do questionário para um total de 54 sujeitos, dentre os quais recebemos o retorno de 37 questionários. Consideramos o retorno do questionário satisfatório, tendo em vista que obtivemos $68 \%$ dos instrumentos respondidos, maior do que a média estimada para esse tipo de pesquisa. Segundo Lakatos e Marconi (2003), a média de retorno para esse tipo de instrumento de coleta fica em torno de $25 \%$.

Para análise das informações contidas no instrumento de pesquisa, utilizamos a Análise de Conteúdo, tendo como referencial teórico Bardin (2011). Buscando ir além do texto escrito, almejamos compreender o que fica subentendido nas mensagens. Enumeramos os questionários a fim de identificar os professores e cruzarmos os dados relativos à idade, formação e atuação de forma específica. Considerando as respostas contidas no instrumento de pesquisa, procuramos compreender como os professores de História inserem as TIC na sua prática docente e quais efeitos eles percebem ao utilizar os recursos tecnológicos. Tal problematização é fundamental, visto que apenas inserir as TIC na prática pedagógica não significa um ensino reflexivo, crítico ou inovador, já que "o vídeo e outras tecnologias tanto podem ser utilizados para organizar como para desorganizar o conhecimento, depende de como e quando os utilizamos". (Moran, 2009, p. 47).

O questionário foi composto por dez questões, sendo cinco questões abertas e cinco questões de múltipla escolha. Os questionamentos visavam saber sobre a carga horária do professor, sua formação, seu conhecimento em relação ao tema, as TIC presentes na escola em que atua, frequência com que usa esses recursos, com quais objetivos utiliza e em quais situações da prática pedagógica.

Quando questionados sobre seu conhecimento em relação ao tema, sete professores relataram não ter conhecimento sobre o assunto; alguns professores não explicitaram o que entendem sobre e outros, apesar de manifestarem seu conhecimento, apresentaram uma visão restrita sobre o uso das TIC ao descreverem que são recursos para utilização em sala de aula. Moran (2009, p. 52) destaca que "as tecnologias podem ajudar a desenvolver habilidades espaçotemporais, sinestésicas, criadoras, mas o professor é fundamental para adequar cada habilidade a um determinado momento histórico e a cada situação de aprendizagem". Do total de 24 professores que relataram ter conhecimento sobre o tema, apenas seis trataram das TIC como recursos tecnológicos a serem utilizados para facilitar e melhorar o processo de ensino e aprendizagem, ou como recurso a ser utilizado na busca de conhecimento de forma interativa, criativa e prazerosa.

Acreditamos que a falta de conhecimento dos professores sobre as TIC ocorra pela falta de formação dos mesmos em relação ao tema, tendo em vista que do total de sujeitos pesquisados, somente nove relataram ter realizado alguma formação nesse campo. Contudo, relatam que a

\footnotetext{
${ }^{4}$ Juntamente com o questionário recolhíamos o termo de consentimento livre esclarecido assinado, com o propósito de viabilizar a utilização dos dados na pesquisa.
} 
formação realizada encontra limites práticos na falta de infraestrutura das escolas. A maioria dos outros professores alega a não realização de cursos devido à falta de tempo, pois possuem uma excessiva carga horária de trabalho, restando pouco tempo para formação continuada, que geralmente é ofertada em horário de descanso ou lazer, não considerando as outras responsabilidades relativas à família, filhos; enfim, relativas à vida pessoal do professor. De acordo com os professores, o ideal seria que os cursos fossem oferecidos em seu turno de trabalho, mas infelizmente não é essa a realidade. Muitos professores relataram que procuram sozinhos por informações sobre o tema. Como destaca uma professora: "a informação que tenho é baseada na minha busca pelo uso das tecnologias, é um aprendizado quase que por necessidade e curiosidade. Ninguém nos oferece formação nesse tema" (professora 26). Outros quatro professores afirmaram que não sabem como utilizar as TIC, embora utilizem alguns recursos como: sala de vídeo ou TV, pendrive para passar filmes e documentários. No entanto, não se sentem preparados para inserir outras tecnologias na sua prática pela falta de conhecimento sobre como utilizá-las.

Concordamos com Moran (2009) quando diz que muitos professores começam a lecionar sem uma formação adequada e acabam por repetir modelos; em alguns casos, devido à excessiva carga horária, em outros por não saberem como fazer. Quando os professores foram questionados sobre tecnologias educacionais, logo se lembraram do computador, recurso a que muitos têm acesso, mas admitem ter dificuldade para utilizá-lo no cotidiano escolar, pois não sabem como fazêlo de forma pedagógica. A respeito do uso do computador, Valente (1999) nos diz que, quando o professor o utiliza, apenas para transmitir o conteúdo ao aluno, ele assume a tarefa de máquina de ensinar, o que ele chama de método tradicional de ensino. Nesse caso, o computador só substitui o livro ou o texto impresso. Porém, quando o professor utiliza o computador para adquirir e reorganizar conhecimentos, essa máquina passa a ser um elemento que possibilita a construção de aprendizagens: "uma máquina para ser ensinada, propiciando condições para o aluno descrever a resolução de problemas, usando linguagens de programação, refletir sobre resultados obtidos e depurar suas ideias por intermédio da busca de novos conteúdos e novas estratégias" (Valente, 1999, p. 2).

Isso não é tarefa fácil, pois é necessário que o professor aprenda a utilizar o computador e adquira conhecimentos além do simples manuseio da máquina. Deve aprender como utilizá-la para o desenvolvimento dos processos de aprendizagem, o que é um desafio a ser enfrentado pelos docentes e pelas instituições educacionais, pois, além da formação do professor e da possibilidade estrutural, é necessária a aceitação da escola e de todos que compõem a comunidade escolar, já que muitos recursos tecnológicos podem ser utilizados no processo de ensino e aprendizagem. Brito e Purificação (2006) exemplificam, dizendo que os filmes são um excelente recurso, desde que sejam utilizados de forma adequada. O professor deve primeiro assistir ao filme e planejar estratégias para a aula; o estudante e a comunidade escolar devem saber o objetivo da atividade e persegui-lo junto com o professor; vai muito além do assistir por assistir, trata-se de imprimir significado epistemológico à atividade. A TV também é um recurso importante na medida em que grande parte dos alunos a assiste e obtém inúmeras informações através dela; cabe ao professor problematizar e explorar essas informações e integrar essas experiências às suas aulas. Porém, para que os recursos possam ser utilizados de forma a contribuir para o processo de ensino e aprendizagem é fundamental, dentre outros, que o professor tenha uma formação adequada.

\section{A UTILIZAÇÃO DAS TIC PELOS PROFESSORES DE HISTÓRIA DA REDE PÚBLICA MUNICIPAL}

Nossa análise sobre a utilização das TIC pelos professores têm como base o questionário preenchido por 35 professores de um total de 26 escolas. Montamos abaixo um quadro apresentando os recursos disponíveis nessas escolas. 
Quadro 1 - Recursos disponíveis nas escolas da rede municipal

\begin{tabular}{|c|c|}
\hline RECURSO & QUANTIDADE DE ESCOLAS QUE DISPÕE \\
\hline Projetor multimídia & 20 \\
\hline Notebook & 19 \\
\hline Sala de informática com internet & 26 \\
\hline Sala de vídeo & 19 \\
\hline TV/Pendrive & 22 \\
\hline TV c/ DVD & 24 \\
\hline Lousa interativa & 1 \\
\hline
\end{tabular}

Fonte: Autoria própria (2020).

Percebemos que ainda há carência de recursos tecnológicos nas escolas, principalmente em relação à quantidade disponível e manutenção dos equipamentos. A título de exemplo: uma professora (professora 18) assinalou que, na escola em que atua, conta como recurso apenas com TV/Pendrive, mas que não há disponibilidade de sala e, por consequência, não consegue utilizar esse recurso em suas aulas. O projetor multimídia, seguido do notebook, são os recursos mais usuais nas escolas, utilizados por aproximadamente $90 \%$ dos professores pesquisados. Normalmente o notebook é utilizado pelo professor em conjunto com o projetor multimídia; é um recurso prático e de fácil manuseio, pois pode ser levado para sala de aula, também possibilita o trabalho com sons e imagens.

A sala de informática com acesso à internet está presente na maioria das escolas. Contudo, apenas 16 professores relataram utilizar esse recurso. O principal motivo destacado para o não uso da sala de informática é a pequena quantidade de computadores e a burocracia para utilizá-los; não há computadores para todos os estudantes e o agendamento prévio comumente demanda um projeto específico para justificar a solicitação. Enfim, é um recurso que poderia ser utilizado por um grande número de professores, mas que possui uma logística truncada para a sua utilização. Fora esses destaques, há também problemas em relação à internet, que muitas vezes não funciona ou sua qualidade é ruim, devido à baixa velocidade de conexão, o que impede o professor de realizar atividades que necessitem da mesma.

Consideramos a sala de informática com acesso à internet um importante recurso a ser utilizado pelos docentes no processo de ensino e aprendizagem, mas, como já mencionado, são necessários investimentos por parte da esfera pública na manutenção, na atualização de programas e softwares, na formação dos professores, na qualidade da conexão de internet e também na quantidade de equipamentos e espaço físico para que o trabalho pedagógico possa ser eficaz. 0 professor, com esse recurso disponível, pode contar com inúmeras possibilidades que potencializam o processo de ensino e aprendizagem dos seus alunos. No que se refere à disciplina de História, pode-se visitar museus, lugares históricos, realizar pesquisas, participar de debates em grupo, acessar banco de dados de bibliotecas digitais, entre outras inúmeras possibilidades. 
A web 2.0, organizada em hipertexto ${ }^{5}$, permite-nos, de acordo com Brito e Purificação (2006), um conhecimento de forma não linear e é de grande importância na busca por informações. Levy também afirma que "o hipertexto ou multimídia interativa são particularmente adequados aos usos educativos" (Levy, 1990, p. 51), visto que esses ambientes permitem a exploração de atividades lúdicas que favorecem uma pedagogia ativa, potencializando o envolvimento dos sujeitos.

Ainda sobre o desenvolvimento das webs cabe destacar a web 3.0 e a web 4.0 que refletem o desenvolvimento da web 2.0 e possibilitam uma interação inteligente bem mais eficaz, pois incorporam as transformações digitais ocorridas na área e realizam de forma mais eficiente atividades que, antes, dependiam do trabalho manual. $\mathrm{O}$ uso da web para reunir informações e fazer recomendações as pessoas que utilizam essas redes é um exemplo claro dessa mudança que altera as relações sociais de diversas formas.

Outro recurso identificado é a sala de vídeo, presente em $54 \%$ das escolas onde atuam os professores pesquisados, sendo que todos os sujeitos da pesquisa afirmaram fazer utilização desse recurso e que normalmente é utilizado por eles para passar algum filme ou documentário aos seus alunos. O que está em questão não é o simples uso dessa tecnologia, mas como e com qual finalidade ela é utilizada. Como já mencionado, muitos professores utilizam filmes e documentários para desenvolver o conteúdo, não contextualizando aquilo que foi visto, o que pode acarretar uma não aprendizagem ou uma aprendizagem não significativa para o estudante.

Para que ocorra uma aprendizagem significativa, é necessário que o professor contextualize o filme ou o documentário apresentado; deixe claros os objetivos com a realização da atividade e, por fim, potencialize o diálogo crítico sobre o que foi assistido. A percepção dos alunos, suas considerações, o debate e a troca de ideias sobre o tema é a grande possibilidade desse tipo de atividade. Quando o professor não explora esses aspectos, perde sentido a utilização de filmes ou documentários. A utilização do recurso deve considerar primeiramente o processo de ensino e aprendizagem, deve estar conectado com os interesses do estudante e com os objetivos da disciplina ministrada. Embora muitos professores utilizem o recurso do vídeo para ilustrar os conteúdos, é relevante destacar que a conexão com o conteúdo é tarefa do professor e, por vezes, o estudante ainda não consegue fazer tais conexões sem o direcionamento docente.

Outro recurso analisado e bastante utilizado nas escolas é a TV Pendrive, também conhecida como TV multimídia, que além de recursos como a entrada para DVD, saídas de áudio, entre outros recursos, permite a exibição de arquivos de áudio, vídeo e imagem através da utilização de dispositivos portáteis como pendrive, HD externo, cartão de memória, entre outros. De um total de 22 professores que disseram haver a disponibilidade desse recurso nas escolas em que atuam, 14 afirmaram fazer a utilização do mesmo. Algumas escolas também dispõem de TV e aparelho de DVD, sendo que de um total de 24 escolas, 11 professores disseram fazer uso desse recurso, mas com pouca frequência.

Analisando os dados que obtivemos, é possível afirmar que os professores que utilizam os recursos tecnológicos, com maior frequência, são os de faixa etária entre 43 a 58 anos, o que nos leva a concluir que, embora esses profissionais tenham nascido e crescido em meio a um contexto social onde havia poucos recursos tecnológicos digitais, buscaram se apropriar deles recursos para inseri-los na sua prática pedagógica. No grupo dos sujeitos que foram investigados, há 13 professores que dizem utilizar os recursos disponíveis nas escolas com maior frequência. Destes, oito estão na faixa etária entre 43 a 58 anos, enquanto cinco estão na faixa dos 29 a 34 anos. Destes sujeitos, encontramos cinco que possuem carga horária semanal de 20 horas, quatro que possuem 40 horas e outros quatro que possuem carga horária acima de 40 horas, o que nos faz concluir que a idade do docente e a carga horária de trabalho semanal não interferem obrigatoriamente na

\footnotetext{
${ }^{5}$ De acordo com Levy, um hipertexto é um software destinado à organização de conhecimentos ou de dados, à aquisição de informações e à comunicação. (Levy, 1990, p. 43)
} 
utilização das TIC pelos mesmos, pois mesmo com as dificuldades encontradas, muitas vezes relacionadas à formação e à carga horária, esses docentes percebem a potencialidade das TIC como mecanismo positivo no processo de ensino e aprendizagem e buscam sua inserção na prática pedagógica.

\section{OBJETIVOS E PERCEPÇÕES DOS PROFESSORES EM RELAÇÃO AO USO DAS TIC'S}

Quando questionados sobre a motivação dos alunos nas aulas que utilizam as TIC, 71\% dos professores afirmaram que sim, que percebem motivação por parte dos alunos. Nesse mesmo questionamento, os professores apontaram pontos positivos e pontos negativos da utilização das TIC como demonstrado no quadro a seguir:

Quadro 2 - Pontos positivos e negativos da utilização das TIC

\begin{tabular}{|c|c|}
\hline Positivos & Negativos \\
\hline Aulas atrativas & Imaturidade dos alunos \\
\hline Alunos participativos & Falta de infraestrutura \\
\hline Aulas interativas & Falta de formação \\
\hline Diversificação da metodologia & \\
\hline Aumento da capacidade interpretativa & \\
\hline Despertam a curiosidade & \\
\hline Aproximação com a realidade & \\
\hline Melhor compreensão do conteúdo & \\
\hline Facilitam a aprendizagem & \\
\hline
\end{tabular}

Fonte: Autoria própria (2020).

Identificamos que a maioria dos professores percebe benefícios no uso das TIC na prática pedagógica e que os alunos ficam mais motivados quando há a inserção dos recursos tecnológicos. Contudo, alguns professores percebem que nem sempre a motivação dos estudantes é positiva e uma das questões levantadas (que se encontra no quadro acima) é em relação à imaturidade dos discentes, ou seja, às vezes os alunos não associam a aula com uso das TIC ao desenvolvimento dos conteúdos das disciplinas; especialmente quando há o uso da internet, logo querendo acessar as redes sociais e usar o recurso para entretenimento. Como exemplo, uma professora diz que: "não ficam motivados pelo uso da tecnologia com interesse no aprendizado. O interesse é apenas em músicas, vídeos, comunicação entre amigos; o uso fica restrito aos seus interesses" (professora 5). Outra professora menciona que nem sempre percebe a motivação por parte dos alunos e diz que: "nem sempre esse uso motiva os alunos, depende do conteúdo e do quanto eles serão protagonistas na atividade proposta" (professora 33). A fala dessa professora vem ao encontro do que foi afirmado anteriormente, ou seja, a tecnologia por si só não é capaz de motivar os alunos e de melhorar a aprendizagem, visto que depende de como o professor vai conduzir sua aula, de como 
ele preparou a utilização desse recurso. Esse estudante, para se sentir motivado, necessita ser protagonista, ele precisa buscar e trocar informações, dar sugestões, opiniões, estar envolvido no processo de ensino e aprendizagem para que os usos das TIC possam de fato fazer alguma diferença no seu aprendizado. Quando questionados sobre os objetivos pretendidos pelos professores ao utilizarem as TIC, obtivemos as seguintes respostas:

\begin{tabular}{|l|c|}
\multicolumn{1}{|c|}{ Quadro 3 - Objetivos dos professores com o uso das TIC } \\
\hline Compreensão do conteúdo através da imagem & $\begin{array}{c}\text { Frequência das } \\
\text { respostas }\end{array}$ \\
\hline Estimular a curiosidade e a produção de conceitos pelo aluno & 2 \\
\hline Sair da rotina da sala de aula & 1 \\
\hline $\begin{array}{l}\text { Proporcionar a interpretação dos conteúdos e relacioná-los à } \\
\text { realidade }\end{array}$ & 1 \\
\hline $\begin{array}{l}\text { Ampliar a informação sobre o tema estudado e facilitar o } \\
\text { entendimento }\end{array}$ & 1 \\
\hline Tornar a aprendizagem mais dinâmica & 1 \\
\hline Fixação do conteúdo & 1 \\
\hline Aulas atrativas & 1 \\
\hline $\begin{array}{l}\text { Habilitar o aluno para a compreensão de diferentes formas de } \\
\text { linguagem e comunicação }\end{array}$ & 1 \\
\hline Ampliar o conhecimento histórico & 1 \\
\hline Não especificou & 2 \\
\hline
\end{tabular}

Fonte: Autoria própria (2020).

As respostas foram diversas, mas percebemos que o principal objetivo dos docentes é potencializar o aprendizado dos conteúdos trabalhados em sala de aula, tendo as TIC como suporte, especialmente por considerarem o som e a imagem como recursos positivos para esse fim. Ainda assim, concluímos que apenas $25 \%$ dos sujeitos pesquisados contextualizam o conteúdo trabalhado em sala de aula e conectam-no ao recurso utilizado.

A maioria dos professores disse fazer uso desse recurso como suporte complementar ao livro didático e percebemos nas respostas de 14 deles, que a utilização dos recursos tecnológicos se dá como substituição da aula convencional, ou seja, são recursos utilizados para ilustrar a aula, para fixação do conteúdo, sem haver por parte dos mesmos a contextualização do recurso utilizado com o conteúdo que esse professor está trabalhando com seus alunos. Principalmente quando se trata de vídeos, a ideia que permeia se dá em torno da imagem, pois muitos professores relataram que utilizam esse recurso para que os alunos tenham uma "ideia", através da imagem, sobre o conteúdo 
estudado, como uma professora ao dizer que "ao passar um vídeo sobre um tópico do conteúdo pretende mostrar visualmente algo contido por escrito no livro didático" (professora 19).

A respeito disso cabe aqui citar Puentedura $(2010)^{6}$, que criou um protocolo para identificar como os professores estão utilizando as TIC's em sala de aula e assim pensar e repensar sua prática pedagógica. Criado na década de 80, o modelo SAMR (The Substitution, Argumentation, Modification and Redefinition Model) identifica quatro níveis de uso das tecnologias. São eles: substituição, ampliação, modificação e redefinição.

No primeiro nível, o da substituição, a tecnologia atua como substituição de outras tecnologias, não havendo mudança funcional como, por exemplo, quando o professor utiliza um editor de texto para escrever em substituição ao lápis e papel. No segundo nível, que é o da ampliação, a tecnologia atua ainda como ferramenta de substituição, mas com melhorias funcionais, ou seja, o professor substitui uma tecnologia antiga por outra mais nova que tenha outras funcionalidades como, por exemplo, a substituição da lousa e do giz por slides através de um projetor multimídia, onde ele pode agregar imagem e som, mas, ainda assim, não há modificação na metodologia e no efeito significativo da aprendizagem. A partir do terceiro nível, inicia-se a transformação. No nível da modificação, há um redesenho da atividade pedagógica, ou seja, a tecnologia é utilizada para modificar, redesenhar a prática pedagógica de forma significativa, como, exemplo, ao utilizar ferramentas tecnológicas para produção, divulgação e acesso de produções, como redes sociais, blogs etc. O último nível, o da redefinição, ocorre quando a tecnologia utilizada permite a execução de tarefas anteriormente inconcebíveis sem essa tecnologia. Nesse nível, a tecnologia faz grande diferença no ensino e na aprendizagem, havendo uma aprendizagem colaborativa e capaz de torná-la significativa, permitindo a criação de novas tarefas, como a produção e o compartilhamento dessa produção em rede.

O que percebemos é que a maioria dos professores pesquisados se encontra nos níveis da substituição e da ampliação, que apesar de apresentarem uma melhoria, não transformam a aprendizagem, tendo em vista que a abordagem dos conteúdos e a prática do professor seguem o modelo tradicional (professor como centro do conhecimento, aluno passivo no processo de aprendizagem, transmissão de conteúdos).

Em relação ao uso da internet, os professores não relataram seus objetivos com a utilização desse recurso ou como planejam a sua utilização, apenas mencionaram que o utilizam para que os alunos façam pesquisas. Consideramos a pesquisa um importante instrumento para aprendizagem, tendo em vista, como já mencionado, a possibilidade de estarmos conectados com o mundo, de visitar lugares, receber informações instantaneamente, participar de fóruns, debates, entre outros. Porém, é preciso que o professor prepare a utilização desse recurso, que indique sites confiáveis para que os estudantes possam realizar a pesquisa, que participe e oriente o trabalho, pois um dos grandes problemas é que muitas vezes os alunos apenas acessam um determinado site e copiam o que está escrito, sem realizar de fato uma pesquisa, sem extrair as informações mais importantes, sem questionar o que está exposto. Guimarães (2015, p. 367) destaca que "a pesquisa em sites didáticos de História requer um esforço do professor e do coletivo de alunos para não reduzir a atividade de pesquisa a uma cópia mecânica".

A atividade que não demanda reflexão abre espaço para a cópia. Moran (2009) diz que caminhamos para a sociedade do conhecimento, mas que, ao mesmo tempo em que dispomos de inúmeras informações, como nunca tivemos antes, temos dificuldades em aproveitar essas informações e em selecionar o que é importante. Com tanta facilidade encontrada a partir das

\footnotetext{
${ }^{6}$ Ruben Puentedura é fundador e presidente da Hippasus, uma empresa de consultoria com sede em Massachusetts, que tem como foco as transformadoras aplicações das tecnologias da informação à educação. É criador do modelo SAMR, para selecionar, utilizar e avaliar a tecnologia na educação. Informação disponível em: http://www.hippasus.com/team/rrpuentedura.html?br=ro\&. Acesso em setembro de 2018.
} 
tecnologias, encontramos o que ele chama de "preguiça intelectual, devido à maior facilidade de copiar e colar, de repetir o previsível" (Moran, 2009, p. 44). Ainda salienta que "o problema da pesquisa não está na internet, mas na maior importância que a escola dá ao conteúdo programático do que à pesquisa como eixo fundamental da aprendizagem" (Moran, 2009, p. 107).

Por fim, a incorporação das tecnologias ao processo pedagógico é algo que requer disponibilidade e disposição, requer preparo sobre como utilizar essas tecnologias do ponto de vista gerencial e didático, sendo necessário capacitar docentes, funcionários e alunos para o bom uso.

\section{ALGUNS MOTIVOS PARA A NÃO UTILIZAÇÃO DAS TIC}

Foi possível identificar, por meio da pesquisa, alguns motivos para a não utilização das TIC pelos professores. Cabe destacar que a maioria dos professores percebe a motivação dos alunos nas aulas em que utilizam as TIC e acreditam ser um recurso que auxilia a prática docente, mas que, muitas vezes, não é utilizado.

Podemos constatar que a maioria dos professores que respondeu essa questão no questionário relatou a falta de infraestrutura nas escolas e a ausência das TIC. Além disso, em relação às salas de informática, geralmente há um número reduzido de equipamentos, que acabam não atendendo à demanda do número de alunos, além da necessidade de o professor ter que agendar a sala com antecedência, o que, muitas vezes, impossibilita a realização de um trabalho com esses recursos. Em relação às salas de vídeo, grande parte afirmou que, muitas vezes, o equipamento é utilizado por alunos e/ou professores de turno inverso, ou seja, para atender alguns projetos presentes nas escolas e, portanto, esse recurso acaba por não estar sempre disponível.

Uma indagação se deu em relação à queixa, por parte dos professores, em relação à infraestrutura das escolas e à ausência das TIC, sendo que a maioria das escolas dispõe de algum recurso tecnológico. Então, nos perguntamos: por que, mesmo havendo recursos tecnológicos e a afirmação por parte dos professores de fazerem uso desses recursos, mais de $77 \%$ apontam como dificuldade a falta de recursos/infraestrutura na escola? Constatamos que apesar das escolas disporem de vários recursos, estes muitas vezes se encontram obsoletos, estragados, sem disponibilidade, tendo em vista o número reduzido de equipamentos para atender à demanda de alunos e professores, além da internet que, muitas vezes, não funciona ou é de velocidade muito baixa, não permitindo que o professor realize o trabalho planejado. Ainda se destaca a ausência de pessoal técnico que os auxilie na instalação e no manuseio dos equipamentos. Sendo assim, como já mencionado anteriormente, não adianta haver salas se os equipamentos forem insuficientes, obsoletos e sem a devida manutenção para que o professor possa, de fato, fazer utilização desses materiais de forma significativa.

Outra dificuldade levantada é em relação à falta de tempo dos professores para preparar as aulas que insiram as TIC. Isso porque muitos professores têm uma carga horária acima de 20 horas semanais. No caso dos nossos sujeitos, a maioria possui uma carga horária semanal de 40 horas ou mais de trabalho. Para que as TIC sejam incorporadas de forma significativa, o professor precisa planejar e organizar a sua prática; se ele não está acostumado a utilizar as tecnologias, vai precisar de mais tempo para estudar e se apropriar do recurso para posteriormente manuseá-lo com os estudantes. Esse tempo de preparo é fundamental, pois o professor precisa preparar seu plano de ensino e organizar a logística necessária para o bom uso das TIC, o que infelizmente nem sempre é possível.

Podemos perceber, portanto, que apesar de os professores afirmarem que há disponibilidade de recursos tecnológicos nas escolas, há uma carência em relação à infraestrutura, especialmente em relação ao número de equipamentos e salas adequadas. Conforme Kenski (2007) 
e Sibilia (2012), é necessário que haja a preocupação no tocante à infraestrutura das escolas, com locais adequados, equipamentos suficientes para atender as demandas dos professores e alunos, manutenção dos equipamentos, atualizações dos hardwares e softwares, para que, de fato, as tecnologias possam integrar-se na prática escolar de forma significativa. Ainda de acordo com Kenski (2007), não adianta impor ao professor que mude sua prática didática, que insira as tecnologias em sala de aula, enquanto o sistema educacional também não mudar, enquanto as escolas continuarem precárias e sem equipamentos ou com equipamentos e softwares ultrapassados e sem manutenção. É fundamental a melhoria na condição de trabalho e de vida do professor, com remuneração digna, menos carga horária de trabalho e formação adequada.

\section{CONCLUSION}

Muitas pesquisas na área da educação indicam as mudanças pelas quais está passando a sociedade e, consequentemente, as escolas. Algumas dessas mudanças, em nosso ponto de vista, são importantes para que haja compatibilidade entre ambas, a exemplo da inserção das TIC no espaço escolar, bem como a formação do professor para incorporar as tecnologias na sua prática pedagógica, de maneira que contribua com o processo de ensino e aprendizagem. Nossa sociedade está permeada por tecnologias, que utilizamos nos mais diversos afazeres. Sendo assim, acreditamos que a escola precisa estabelecer estratégias de apropriação desses mecanismos. Assim como o fato de que o uso pedagógico das tecnologias possa fazer a diferença, desde que utilizadas adequadamente, tornando as aulas mais atrativas para nossas crianças, adolescentes e jovens que vivem cercados dos mais diversos aparatos tecnológicos e recebem informações através dos mais diversos meios de informação e comunicação.

Constatamos que as escolas que fazem parte do escopo dessa pesquisa são carentes de recursos tecnológicos, especialmente em relação à quantidade de equipamentos e espaço físico para a instalação desses recursos. Isso significa que mesmo que as escolas disponham de determinados recursos tecnológicos, geralmente eles são insuficientes para atender a demanda existente, necessitando de agendamento prévio para que possam ser utilizados em pequenos grupos. Citamos como exemplo a sala de vídeo e a sala de informática; consideramos o acesso à internet um importante recurso para o processo de ensino e aprendizagem. As salas de informática estão presentes em $81 \%$ das escolas pesquisadas, contudo seu aproveitamento é limitado, sendo utilizadas por $45 \%$ dos docentes. Segundo os professores, a pouca utilização desse recurso se deve à falta de equipamentos suficientes para uso individual dos estudantes, como também a falta de internet ou internet com baixa velocidade de conexão, o que inviabiliza o trabalho.

Os professores participantes dessa pesquisa apontam fazer maior uso de vídeos, internet e slides, considerando o audiovisual como um importante recurso a ser utilizado em sala de aula. Contudo, foi possível identificar que a maioria dos docentes desenvolve uma prática pedagógica centrada no professor, onde as TIC são utilizadas para substituir recursos convencionais como lousa, giz, livro didático e materiais impressos e cumprem o objetivo de ilustrar o conhecimento.

Do total dos participantes desta pesquisa, $25 \%$ relataram utilizar as TIC para contextualizar o conteúdo, direcionando o aluno a compreender e a construir o conhecimento histórico. Ainda assim, quatro professores mencionaram a utilização das TIC de maneira a modificar a atividade pedagógica, onde os estudantes produzem conhecimentos e compartilham o que é produzido com os outros, através de blogs, redes sociais e outros recursos disponíveis. Também fica evidente a necessidade de superar diversas barreiras, que impedem esses docentes de fazer um uso mais eficaz das TIC, como a falta de formação. Dentre nossos pesquisados, somente $25 \%$ realizaram algum curso de formação sobre a utilização das TIC. Essa falta de formação contribui para que muitos professores resistam em inserir as tecnologias em sala de aula, pois se sentem despreparados para incorporar esses recursos em sua prática pedagógica. 
Por fim, acreditamos que as TIC podem ser recursos importantes para auxiliar o professor na sua prática pedagógica, a fim de contribuir com o processo de ensino e aprendizagem. Não se trata de utilizar as tecnologias como máquinas para ensinar e aprender, mas como ferramentas pedagógicas que podem promover e motivar a investigação, a curiosidade e a construção do conhecimento histórico.

Authors' Contributions: Paste the contributions of each author.

Simone Weber Cardoso Schneider: conception and design, acquisition of data, analysis and interpretation of data, drafting the article, critical review of important intellectual content. Adriana Duarte Leon: conception and design, acquisition of data, analysis and interpretation of data, drafting the article, critical review of important intellectual content. All authors have read and approved the final version of the manuscript.

Ethics Approval: Not applicable.

Acknowledgments: Not applicable.

\section{REFERENCES}

Alves, E. P. M. (2019). A digitalização do simbólico e o capitalismo cultural-digital: a expansão dos serviços culturaisdigitais no Brasil. Sociedade E Estado, 34(01), 129-157.

Bardin, L. (2011). Análise de Conteúdo. São Paulo: SP Edições.

Bogdan, R., \& Biklen, S. K. (1994). Investigação qualitativa em educação: uma introdução à teoria e aos métodos. Portugal: Porto.

Brito, G. S., \& Purificação. I. (2006). Educação e novas tecnologias: um re-pensar. Curitiba: Ibpex.

Burch, S. (2005). Sociedade da informação e sociedade do conhecimento. In. A.A, V.P, D.P. (orgs). Desafios de palavras: enfoques multiculturais sobre as sociedades da informação. Paris: C \& F Éditions.

Cardoso, T., \& Pestana, F. (2020). A Wikipédia como prática e recurso educacional aberto na formação docente. Revista Tempos e Espaços em Educação, 13(32), 1-16. https://doi.org/10.20952/revtee.v13i32.14275.

Figueiredo, A.D. (2002). Redes e educação: a surpreendente riqueza de um conceito. In: Conselho Nacional de Educação. Redes de aprendizagens, Redes de conhecimento. Lisboa: Conselho Nacional de Educação, Ministério da Educação.

Figueiredo, T. D., \& Rodrigues, S. C. (2020, ) Professores e suas tecnologias: uma cultura docente em ação. Educação em Revista, 36, 1-25.

Gil, A. C. (2008). Métodos e técnicas de pesquisa social. São Paulo: Atlas S.A.

Guimarães, S. (2015). Didática e prática de ensino de História: Experiências, reflexões e aprendizados. Campinas: Papirus.

Kenski . V. M. (2007). Educação e tecnologias: o novo ritmo da informação. Campinas: Papirus.

Kenski, V. M. (1998). Novas tecnologias: o redimensionamento do espaço e do tempo e os impactos no trabalho docente. Revista Brasileira de Educação. 8, 58-71.

Lakatos, E. M., \& Marconi, M. A. (2003). Fundamentos de metodologia científica. São Paulo: Atlas.

Lévy, P. (2010). Cibercultura. São Paulo: Editora 34.

Lévy, P. (1990). As tecnologias da inteligência: o futuro do pensamento na era da informática. Lisboa: Instituto Piaget.

Minayo, M.C.de S. (2009). Pesquisa social: teoria, método e criatividade. Petrópolis: Vozes.

Moran, J. M. (2000). Mudar a forma de ensinar e de aprender: transformar as aulas em pesquisa e comunicação presencial-virtual. Revista Interações, 5(9), 57-72.

Moran, J. M. (2009). A educação que desejamos: Novos desafios e como chegar lá. Campinas: Papirus.

Moran, J. M. (2015). Mudando a educação com metodologias ativas. In: Souza, C. A. \& Morales, O. E. T. (orgs.) Coleção Mídias Contemporâneas. Convergências Midiáticas, Educação e Cidadania: aproximações jovens, 2, 15-33.

Oliveira, D. (2012). Professor pesquisador em Educação Histórica. Curitiba: Intersaberes. 
Oliveira, M. R. N. S. (2001). Do mito da tecnologia ao paradigma tecnológico; a mediação tecnológica nas práticas didático-pedagógicas. Revista Brasileira de Educação, 18, 101-107.

Pinto, C. da C., \& Pretto, N. (2006). Tecnologias e novas educações. Revista Brasileira de Educação, 31 (11), $19-30$.

Porto, T. M. E. (2006). As tecnologias da comunicação e informação na escola; relações possíveis...relações construídas. Revista Brasileira de Educação, 11 (31), 43-57.

Porto, T. M. E. (2009). Inserções das tecnologias e meios de comunicação em escola públicas do ensino fundamental: uma realidade em estudo. Revista Linhas, 10(2), 34-59.

Prenski, M. (2018). Digital Natives Digital Immigrants. Horizon: NCB University Press.

Pretto, N. (1999). Educação e inovação tecnológica: um olhar sobre as políticas públicas brasileiras. Revista Brasileira de Educação, 11, 75-85.

Pretto, N. (2002). Espaço aberto: formação de professores exige rede! Revista Brasileira de Educação. 20, 121-131,

Puentedura, R. (2010). SAMR and TPCK: Intro to Advanced Practice.

Sibilia, P. (2012). Redes ou paredes: a escolas em tempos de dispersão. Rio de Janeiro: Contraponto.

Valente, J. A. (1999). O computador na sociedade do conhecimento. Campinas: NIED/ UNICAMP.

Received: 27 de Julho de 2020 | Accepted: 22 de Fevereiro de 2021 | Published: 25 Abril de 2021

This is an Open Access article distributed under the terms of the Creative Commons Attribution License, which permits unrestricted use, distribution, and reproduction in any medium, provided the original work is properly cited. 